\title{
Blockchain and it's Applications in Various Fields
}

\author{
Allin Geo Varghese, R. Kavitha, G. Michael
}

\begin{abstract}
Automatic international has delivered efficiencies, new ingenious items, and close customer connections all round with the aid of the a success usage of transportable, IoT (net of factors), on-line life, exam and cloud innovation to create models for higher selections. Blockchain is as of late presented and altering the computerized global conveying some other point of view to security, flexibility and effectiveness of frameworks. at the same time as at the start promoted via Bitcoin, Blockchain is considerably greater than an established order for virtual foreign money. It gives a secure technique to trade any sort of right, management, or change. Mechanical development regularly is based upon confided in organizations; but expanding manage, cybercrime and extortion are repressing extension. To cope with these difficulties, Blockchain will empower more mild-footed esteem chains, quicker object improvements, nearer consumer connections, and swifter incorporation with the IoT and cloud innovation. Facilitate Blockchain furnishes a decrease price of trade with a believed contract checked without mediation from outsider.
\end{abstract}

Keywords.Blockchain

\section{INTRODUCTION}

The presentation of digital forms of money, particularly Bitcoin, has brought the idea of blockchain innovation into the standard. A blockchain is a persistently developing dispersed database that ensures against altering and amendment of information. The business has just observed the intensity of a dispersed framework with Git Version control; blockchain expands on the equivalent Merkle tree approach, yet additionally includes accord, which indicates runs on how information can be included and checked. Exchanges are included squares and should pursue the correct request in which they occurred (in this manner the name blockchain).

Bitcoin uses blockchain to keep up its open record of every last trade anytime made with Bitcoin. This Merkle tree approach mulls over a more significant hashing framework to give compelling and secure affirmation of a great deal of data. This information is then used by Bitcoin to approve their esteem based checks.

Revised Manuscript Received on July 22, 2019.

Allin Geo Varghese, Department of Computer Science and Engineering, Bharath Institute of Higher education and research, Chennai , India

Dr.R.Kavitha Department of Computer Science and Engineering, Bharath Institute of Higher education and research, Chennai , India

Dr.G.Michael, Department of Computer Science and Engineering, Bharath Institute of Higher education and research, Chennai , India
Blockchain isn't simply restricted to the money related framework; rather, it is an extraordinary answer for any stage or item that requires trust, for example, keyless vehicle section validation. Furthermore, IBM and Samsung as of late uncovered a proof of idea that utilization blockchain as the foundation of the Internet of Things.

Blockchain likewise can possibly enhance frameworks as of now being used all through society. [1],[3],[5]

A report done by the territory of Virginia uncovered that most casting a ballot machines put by and by somewhere in the range of 2002 and 2014 utilized the passwords 'abcde' and 'administrator,' which means they could have effectively been hacked from the parking [2 ],[ 4],[6]areas outside of the surveying stations. By executing a blockchain-based casting a ballot framework, races can turn out to be significantly more secure.

The thought behind blockchain, to put it plainly, is to have the capacity to build up and confirm trust without the need of an incorporated framework. Rather, this power would be given to a decentralized system, making it more secure as well as both more productive and quicker proportional. A decentralized commercial center can supplant showcase pioneers like Ebay, Amazon, and Uber. This would imply that trust, rules, character, notoriety, and installment decisions would be implanted at the client level and members arrive officially trusted and decentrally recognized.

Blockchain innovation offers a considerable measure of conceivably problematic power, and organizations are as of now in the race for various item contributions. Bitcoin uses blockchain to keep up its open record of every last trade anytime made with Bitcoin. [7],[ 9] ,[11]

This Merkle tree approach mulls over a more significant hashing framework to give compelling and secure affirmation of a great deal of data. This information is then used by Bitcoin to approve their esteem based checks.

Blockchain isn't simply restricted to the money related framework; rather, it is an extraordinary answer for any stage or item that requires trust, for example, keyless vehicle section validation. Furthermore, IBM and Samsung as of late uncovered a proof of idea that utilization blockchain as the foundation of the Internet of Things. 


\section{Blockchain and it's Applications in Various Fields}

\section{A.Blockchain:}

Blockchains document agree with like an atomic clock data time. in place of agree with, [8],[ 10] ,[12]

time strolls ever ahead and is irreversible. Envision a state of affairs where accept as true with may be recorded alongside those strains, with the surprisingly equal exactness and dedication. trust may be misplaced right while it's far grabbed through virtue of our reliance on experiential, stupid and primary techniques for narrative it. whilst a person says "consider me" it typically initiates question[14],[ 16], [18]

Blockchain advancement can exchange that. consistently throughout the beyond 18 years, Edelman, an typical selling company, has issued a report called the trust The deterioration of institutional believe is borne, in no little degree, out of dinkiness, instructive asymmetries and office problems that prop up the modern state of affairs and crushing stacked associations. other than ecological exchange, first rate pay awkwardness and pandemics, the overall trust insufficiency may be one of the international's direst troubles - observing that they are via and thru interconnected. The accept as true with insufficiency is the wellspring that floods the seeds of political threat and social polarization pivoting the workshop on globalization and multilateralism.

Against this difficult scenery, blockchains are no panacea, but with the proper blend of authority and institutional movements from simple to superior, and inevitably to decentralized systems, we are able to begin capturing the agree with shortfall. Markets, customers, speculators and exceptional partners have all end up worn out on finding out about the offenses of large associations amid uncommon appears of daytime that creeps thru the fissure. late models incorporate Equifax administrators offering inventory days after a big rupture turned into located that uncovered about the entire U.S. staff to a lifetime of character and budgetary risk. The immense report fixing outrage at Wells Fargo is some other ongoing precedent that planned to fuel developing doubt and outrage inside the market. corporations and foundations are reacting to this consider shortfall from various perspectives, frequently with the inverse anticipated consequences. Starbucks' ongoing choice to close 8,000 its U.S. shops on may additionally 29 in mild of the treacherous capture of two dim supporters at a shop in Philadelphia may be such an ejection to get better consider. The moderate and particularly tone-almost deaf response from Mark Zuckerberg, facebook's media-modest CEO, following the Cambridge Analytica disgrace, which might also have had desire affecting outcomes, emphatically brought to fb'strustBarometer. even as the exam is a persuading delineation in time of typical manners and attitude on accept as true with out in the open and private foundations, the all the all the greater charming bits of gaining knowledge of are collected via searching collection of work longitudinally. by means of this degree, Edelman's most recent accept as true with Barometer certifies the assessments we've got visible riding tremendous results in surveying stations, on roads and inside the market.

The astonishing Brexit vote and the choice of President Trump, which was a veritable trans-Atlantic resonate where voters sowed the seeds of their uncertainty in nothing new autonomous of the outcomes, are two substantial scale level points of reference of the trust lack. Beyond question, following the Brexit vote, examine terms for "what is Brexit?" and even more troublingly, "what is the EU?" spiked in the U.K., showing the burnable political mix of defiant penchants, blended with populism and two-speed monetary recovery. Various surveyors and specialists missed precisely how significant this wellspring of uncertainty genuinely is and only six day by day papers in the U.S The deterioration of institutional believe is borne, in no little degree, out of dinkiness, instructive asymmetries and office problems that prop up the modern state of affairs and crushing stacked associations. other than ecological exchange, first rate pay awkwardness and pandemics, the overall trust insufficiency may be one of the international's direst troubles - observing that they are via and thru interconnected. The accept as true with insufficiency is the wellspring that floods the seeds of political threat and social polarization pivoting the workshop on globalization and multilateralism.against this difficult scenery, blockchains are no panacea, but with the proper blend of authority and institutional movements from simple to superior, and inevitably to decentralized systems, we are able to begin capturing the agree with shortfall. Markets, customers, speculators and exceptional partners have all end up worn out on finding out about the offenses of large associations amid uncommon appears of daytime that creeps thru the fissure. late models incorporate Equifax administrators offering inventory days after a big rupture turned into located that uncovered about the entire U.S. staff to a lifetime of character and budgetary risk. The immense report fixing outrage at Wells Fargo is some other ongoing precedent that planned to fuel developing doubt and outrage inside the market. corporations and foundations are reacting to this consider shortfall from various perspectives, frequently with the inverse anticipated[19],[21],[23]

consequences. Starbucks' ongoing choice to close 8,000 its U.S. shops on may additionally 29 in mild of the treacherous capture of two dim supporters at a shop in Philadelphia may be such an ejection to get better consider. The moderate and particularly tone-almost deaf response from Mark Zuckerberg, facebook's media-modest CEO, following the Cambridge Analytica disgrace, which might also have had desire affecting outcomes, emphatically brought to fb'stru

\section{LITERATURE SURVEY}

A.Efficient key management scheme for health blockchainSocial insurance is a major application situation of blockchain, and blockchains utilized in human services are called wellbeing blockchain. All in all, blockchain squares are open and the exchanges in them are open. On the off chance that some protection information are engaged with these exchanges, they will be spilled. Attributable to medicinal services framework including a lot of protection information,certain security components must be worked to ensure these protection information in wellbeing 
blockchain. Besides, on the grounds that the center of security instruments is the key administration plots, the suitable key administration plans ought to be planned before blockchains can be utilized in human services framework. [20],[22], [24]

Here, as indicated by the highlights of wellbeing blockchain, the creators utilize a body sensor system to plan a lightweight reinforcement and productive recuperation conspire for keys of wellbeing blockchain. The creators' examinations demonstrate that the plan has high security and execution, and it tends to be utilized to ensure security messages on wellbeing blockchain adequately and to advance the use of wellbeing block chain.

\section{B Using Blockchain Technology for Government Auditing}

The current investigation go for giving blockchain innovation for government reviewing that direct by government reviewers in general society area. The fundamental thought of this examination is to attract the issue and machine to blockchain innovation for authorities examining. this system lets in to remember inspecting system like chess considering the fact that managed approaches are pondered from all interrelated and subsidiary sides, considering the time thing. sooner or later we came to resolution that utilizing everyday blockchain and computerized advances is an ideal method to keep any sort of extortion [25],[27],[29].

\section{Recipient-orientated Transaction for terminating Double pay attacks in personal Blockchain}

Twofold spending attacks by using the idea of beneficiary ideas in non-public blockchain structures. together with the ideas of stealth address and master node at inheritor sides, value-based security is guaranteed and exchange beneficiaries move toward becoming dynamic which get exchange proliferation singularly. In view of this methodology, it very well may be demonstrated that beneficiary situated technique is recommended for keeping the twofold spending assaults in this paper. Also, the proposed strategy is conceivable to avoid twofold investing assaults utilizing the confirmation energy of the beneficiary and blocking time of the exchange.

\section{ADVANTAGE OF BLOCKCHAIN}

Transparence one of the high motives blockchain is fascinating to organizations is that this innovation is pretty frequently open source. that suggests unique customers or engineers have the chance to alternate it as they see fit. in any case, what's most critical about it being open supply is that it makes modifying logged facts internal a blockchain unimaginably troublesome. All matters considered, if there are innumerable eyes on the device, any individual is maximum in all likelihood going to look that logged records has been adjusted. This makes blockchain an particularly at ease innovation.

\section{Reduced transaction}

As stated, blockchain enables disbursed and business-to-enterprise exchanges to be finished without the requirement for an interloper, that is regularly a bank. for the reason that there may be no mediator inclusion connected to blockchain exchanges, it implies they are able to clearly lessen costs to the client or corporations after some time. [26],[28],[30]

\section{E. Faster transaction settlements .}

With reference to commonplace banks, it is normal for exchanges to take days to totally settle. this is due to conventions in bank replacing programming, and in addition the manner that financial corporations are simply open amid normal enterprise hours, 5 days seven days. You likewise have monetary foundations situated in exclusive time zones the world over, which could defer getting ready times. similarly, blockchain innovation is operating 24 hours each day, seven days seven days, this means that blockchain-based totally exchanges manner impressively extra unexpectedly.

\section{F. Decentralization}

Any other focal motive blockchain is so energizing is its absence of a focal data middle. instead of walking a colossal server farm and checking exchanges through that middle point, blockchain clearly permits singular exchanges to have their very own proof of legitimacy and the approval to uphold those imperatives. With statistics on a particular blockchain piecemealed at some stage in the arena on person servers, it ensures that if this statistics fell into undesirable hands (e.g., a digital crook), only a little degree of statistics, and now not the whole gadget, might be imperiled.

User-controlled networks

In conclusion, digital currency financial specialists are will in general be extremely supported by the control part of blockchain. As opposed to hosting a third get-together run the show, clients and engineers are the ones who get the chance to give orders. For example, a failure to achieve a $80 \%$ accord on a redesign attached to bitcoin's blockchain is the thing that required a fork into two separate monetary forms (bitcoin and bitcoin money) over four months prior. Having a say runs far with speculators and designers.

\section{LIMITATIONS}

\section{Extremely labile}

The virtual monetary paperwork that depend on blockchain innovation are very exposed to amazing unpredictability. obviously, one excellent case for that is the fluctuating charges of Bitcoin that change from ordinary. One reason behind that excellent unpredictability is that both the decentralized blockchain innovation and the digital economic forms are 


\section{Blockchain and it's Applications in Various Fields}

substantially new to the market. Which implies that the businesses, monetary experts, governments, and one-of-a-kind gatherings receiving or no longer embracing them will noticeably affect the unpredictability. The Bitcoin value dropped $\$ 2$ hundred on the day whilst China selected to prohibition on companies from bringing ICOs up in 2017. that is an incredible drop and this type of instability is troubling folks who are considering putting sources into Bitcoin or a few different digital money besides.

\section{H. Misdemeanour}

In perspective on the anonymity that exists in decentralized blockchain and virtual money related norms which rely upon them, they have transformed into a second home for each and every unlawful trade. One extraordinary event for that is "Silk Road," an electronic black market. [31],[33],[35]

People utilized this phase to purchase things like illicit trades using blockchain-based virtual fiscal gauges. Regardless, the FBI shut this spot down in the wake of taking in its existence. Without a doubt, even it was shut down, various people still envision this decentralized advancement is exorbitantly charming, making it difficult to guilty parties.'

Securing virtual fiscal measures that are blockchain-based are a noteworthy cerebral agony for people who are not too instructed. When in doubt, moored limit is basic for customers who think about advancement. Really, it will in general be capable basically by methods for buying "Cool accumulating" wallets like Trezor. Regardless, people who can't manage advancement may go up against an issue with making a Bitcoin or Ethereum wallet and a short time later trading coins from a mechanized wallet to a cool accumulating wallet. Thusly, various people who guarantee computerized types of cash are securing their coins on the exchanges. This could be an issue for customers as snoops normally target cryptographic cash exchanges and one case for that is Mt. Gox. As needs be, the exchange had lost $\$ 460$ million. [37],[39],[41]

\section{CONCLUSION}

Some trust that it will help in making cryptographic forms of money which will end up being a potential adversary to valuable metals while others trust that it is before long going to blast like an air pocket and nothing more. [38],[40],[42] In any case, blockchain innovation is one of the extraordinarily imaginative creations that innovation has ever observed. So how we utilize it is dependent upon us. While the discussion is as yet going on its probability and difficulties, a few organizations, for example, Overstock.com and Tesla have just begun tolerating virtual monetary standards that depend on the blockchain. In any case, it is as yet not obvious what the retail pioneers like Amazon and eBay would do with the digital money acknowledgment

\section{REFERENCES}

A., Rangarajan K.,Algorithm for automaton specification for exploring dynamic labyrinths,Indian Journal of Science and
Technology,V-6,I-SUPPL5,PP-4554-4559,Y-2013

[2] P. Kavitha, S. Prabakaran "A Novel Hybrid Segmentation Method with Particle Swarm Optimization and Fuzzy C-Mean Based On Partitioning the Image for Detecting Lung Cancer" International Journal of Engineering and Advanced Technology (IJEAT) ISSN: 2249-8958, Volume-8 Issue-5, June 2019

[3] Kumaravel A., Meetei O.N.,An application of non-uniform cellular automata for efficient cryptography,2013 IEEE Conference on Information and Communication Technologies, ICT 2013,V-,I-,PP-1200-1205,Y-2013

[4] Kumarave A., Rangarajan K.,Routing alogrithm over semi-regular tessellations,2013 IEEE Conference on Information and Communication Technologies, ICT 2013,V-,I-,PP-1180-1184,Y-2013

[5] P. Kavitha, S. Prabakaran "Designing a Feature Vector for Statistical Texture Analysis of Brain Tumor" International Journal of Engineering and Advanced Technology (IJEAT) ISSN: 2249-8958, Volume-8 Issue-5, June 2019

[6] Dutta P., Kumaravel A.,A novel approach to trust based identification of leaders in social networks,Indian Journal of Science and Technology,V-9,I-10,PP--,Y-2016

[7] Kumaravel A., Dutta P.,Application of Pca for context selection for collaborative filtering,Middle - East Journal of Scientific Research,V-20,I-1,PP-88-93,Y-2014

[8] Kumaravel A., Rangarajan K.,Constructing an automaton for exploring dynamic labyrinths,2012 International Conference on Radar, Communication and Computing, ICRCC 2012,V-,I-,PP-161-165,Y-2012

[9] P. Kavitha, S. Prabakaran "Adaptive Bilateral Filter for Multi-Resolution in Brain Tumor Recognition" International Journal of Innovative Technology and Exploring Engineering (IJITEE) ISSN: 2278-3075, Volume-8 Issue-8 June, 2019

[10] Kumaravel A.,Comparison of two multi-classification approaches for detecting network attacks, World Applied Sciences Journal,V-27,I-11,PP-1461-1465,Y-2013

[11] Tariq J., Kumaravel A.,Construction of cellular automata over hexagonal and triangular tessellations for path planning of multi-robots,2016 IEEE International Conference on Computational Intelligence and Computing Research, ICCIC 2016,V-,I-,PP--,Y-2017

[12] Sudha M., Kumaravel A.,Analysis and measurement of wave guides using poisson method,Indonesian Journal of Electrical Engineering and Computer Science,V-8,I-2,PP-546-548,Y-2017

[13] Ayyappan G., Nalini C., Kumaravel A.,Various approaches of knowledge transfer in academic social network, International Journal of Engineering and Technology,V-,I-,PP-2791-2794,Y-2017

[14] Kaliyamurthie, K.P., Sivaraman, K., Ramesh, S. Imposing patient data privacy in wireless medical sensor networks through homomorphic cryptosystems 2016, Journal of Chemical and Pharmaceutical Sciences 92.

[15] Kaliyamurthie, K.P., Balasubramanian, P.C. An approach to multi secure to historical malformed documents using integer ripple transfiguration 2016 Journal of Chemical and Pharmaceutical Sciences 92.

[16] A.Sangeetha,C.Nalini,"Semantic Ranking based on keywords extractions in the web", International Journal of Engineering \& Technology, 7 (2.6) (2018) 290-292

[17] S.V.GayathiriDevi,C.Nalini,N.Kumar,"An efficient software verification using multi-layered software verification tool "International Journal of Engineering \& Technology, 7(2.21)2018 454-457

[18] C.Nalini,ShwtambariKharabe,"A Comparative Study On Different Techniques Used For Finger - Vein Authentication", International Journal Of Pure And Applied Mathematics, Volume 116 No. 8 2017, 327-333, Issn: 1314-3395

[19] M.S. Vivekanandan and Dr. C. Rajabhushanam, "Enabling Privacy Protection and Content Assurance in Geo-Social Networks", International Journal of Innovative Research in Management, Engineering and Technology, Vol 3, Issue 4, pp. 49-55, April 2018.

[20] Dr. C. Rajabhushanam, V. Karthik, and G. Vivek, "Elasticity in Cloud Computing", International Journal of Innovative Research in Management, Engineering and Technology, Vol 3, Issue 4, pp. 104-111, April 2018.

[21] K. Rangaswamy and Dr. C. Rajabhushanamc, "CCN-Based Congestion Control Mechanism In Dynamic Networks", International Journal of Innovative Research in Management, Engineering and Technology, Vol 3, Issue 4, pp. 117-119, April 2018.

[22] Kavitha, R., Nedunchelian, R., "Domain-specific Search engine optimization using healthcare 
ontology and a neural network backpropagation approach", 2017, Research Journal of Biotechnology, Special Issue 2:157-166

[23] Kavitha, G., Kavitha, R., "An analysis to improve throughput of high-power hubs in mobile ad hoc network", 2016, Journal of Chemical and Pharmaceutical Sciences, Vol-9, Issue-2: 361-363

[24] Kavitha, G., Kavitha, R., "Dipping interference to supplement throughput in MANET" , 2016, Journal of Chemical and Pharmaceutical Sciences, Vol-9, Issue-2: 357-360

[25] Michael, G., Chandrasekar, A.,"Leader election based malicious detection and response system in MANET using mechanism design approach", Journal of Chemical and Pharmaceutical Sciences(JCPS) Volume 9 Issue 2, April - June 2016

[26] Michael, G., Chandrasekar, A.,"Modeling of detection of camouflaging worm using epidemic dynamic model and power spectral density", Journal of Chemical and Pharmaceutical Sciences(JCPS) Volume 9 Issue 2, April - June 2016 .

[27] Pothumani, S., Sriram, M., Sridhar, J., Arul Selvan, G., Secure mobile agents communication on intranet,Journal of Chemical and Pharmaceutical Sciences, volume 9, Issue 3, Pg No S32-S35, 2016

[28] Pothumani, S., Sriram, M., Sridhar, Various schemes for database encryption-a survey, Journal of Chemical and Pharmaceutical Sciences, volume 9, Issue 3, Pg NoS103-S106, 2016

[29] Pothumani, S., Sriram, M., Sridhar, A novel economic framework for cloud and grid computing, Journal of Chemical and Pharmaceutical Sciences, volume 9, Issue 3, Pg No S29-S31, 2016

[30] Priya, N., Sridhar, J., Sriram, M. "Ecommerce Transaction Security Challenges and Prevention Methods- New Approach" 2016 ,Journal of Chemical and Pharmaceutical Sciences, JCPS Volume 9 Issue 3.page no:S66-S68 .

[31] Priya, N.,Sridhar,J.,Sriram, M.“Vehicular cloud computing security issues and solutions" Journal of Chemical and Pharmaceutical Sciences(JCPS) Volume 9 Issue 2, April - June 2016

[32] Priya, N., Sridhar, J., Sriram, M. "Mobile large data storage security in cloud computing environment-a new approach" JCPS Volume 9 Issue 2. April - June 2016

[33] Anuradha.C, Khanna.V, "Improving network performance and security in WSN using decentralized hypothesis testing "Journal of Chemical and Pharmaceutical Sciences(JCPS) Volume 9 Issue 2, April - June 2016.

[34] Anuradha.C, Khanna.V, "A novel gsm based control for e-devices" Journal of Chemical and Pharmaceutical Sciences(JCPS) Volume 9 Issue 2, April - June 2016 .

[35] Anuradha.C, Khanna.V, "Secured privacy preserving sharing and data integration in mobile web environments " Journal of Chemical and Pharmaceutical Sciences(JCPS) Volume 9 Issue 2, April - June 2016.

[36] Sundarraj, B., Kaliyamurthie, K.P. Social network analysis for decisive the ultimate classification from the ensemble to boost accuracy rates 2016 International Journal of Pharmacy and Technology 8

[37] Sundarraj, B., Kaliyamurthie, K.P. A content-based spam filtering approach victimisation artificial neural networks 2016 International Journal of Pharmacy and Technology 83 .

[38] Sundarraj, B., Kaliyamurthie, K.P. Remote sensing imaging for satellite image segmentation 2016 International Journal of Pharmacy and Technology 8 3.

[39] Sivaraman, K., Senthil, M. Intuitive driver proxy control using artificial intelligence 2016 International Journal of Pharmacy and Technology $8 \quad 4$.

[40] Sivaraman, K., Kaliyamurthie, K.P. Cloud computing in mobile technology 2016 Journal of Chemical and Pharmaceutical Sciences 92.

[41] Sivaraman, K., Khanna, V. Implementation of an extension for browser to detect vulnerable elements on web pages and avoid click jacking 2016 Journal of Chemical and Pharmaceutical Sciences 92.

\section{AUTHORS PROFILE}

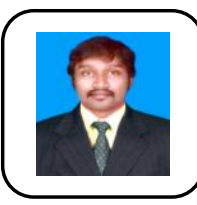

Allin Geo Varghese, Associate Professor, Department of Computer Science \& Engineering, Bharath Institute of Higher Education and Research, Chennai, India

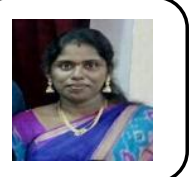

Dr. R.Kavitha, Associate Professor, Department of Computer Science \& Engineering, Bharath Institute of Higher Education and Research, Chennai, India

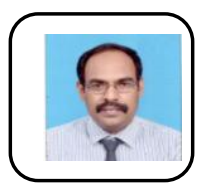

G. Michael, Associate Professor, Department of Computer Science \& Engineering, Bharath Institute of Higher Education and Research, Chennai, India 